\title{
The Fourth European Trainees Forum
}

\author{
Peter Cornwall and Laurence Sheldon
}

The Fourth European Trainees Forum met in Lisbon in April 1996. Twenty-six delegates from 14 countries came together to discuss psychiatric training in the European context. New to the Forum was Austria, with the result that now all the countries of the European Union training psychiatrists are members of the Forum, with Norway and Switzerland present as well. The meeting began with a morning conference for Portuguese trainees on The identity of the psychiatrist in the 21st century', followed by a day and a half of round-table discussions.

One of the aims of the Forum has been to expand activity between its annual meetings. Over the past year the Forum has had observer status on the European Boards for Psychiatry and Child and Adolescent Psychiatry. This allowed proposing amendments to the Charters on the Minimum Requirements for Specialist Training in the European Union. Forum members also contributed to a symposium on training in Strasbourg in October 1995 organised by the Association of European Psychiatrists (AEP).

Two important training issues were discussed in detail - quality assurance of training institutions and requirements for supervisors of training. Only four countries - Ireland, The Netherlands, Norway and the UK - have a system of inspection visits which include a trainee on the approval team; the majority have no national inspection process at all. Indeed, on hearing of the approval visit system that exists in the UK and Ireland, one representative exclaimed that it must be paradise to work as a trainee herel The Forum has recommended that a national system of regular inspection visits with trainee involvement should be a mandatory requirement of national training programmes. On the matter of supervision, it is clear that this is variable both within and between countries. Interestingly, representatives from The Netherlands and Germany stressed the distinction between the 'trainer' who provides the trainee with day to day clinical advice and the 'supervisor' who monitors the trainee's progress on a weekly basis but with a longer-term perspective. The Forum agreed that 'supervisors' need specific training in how to perform their task.

Significant progress continues to be made in the formation of national trainees' organisations. Whereas three years ago only four countries had established them, organisations now exist in Denmark, Finland, Greece, Ireland, Italy, The Netherlands, Portugal, Spain, Sweden and the UK. Next year the Forum will be hosted by Greek trainees in Athens. This will create an opportunity for the Forum to seek representation from Central and Eastern European countries. Contacts have been made with trainees in Albania, Bulgaria, Estonia, Hungary, Lithuania, Romania and the former Yugoslavia, but it is unlikely that all these countries will be able to send representatives because of financial constraints. The Forum itself is now self-financing and at the next meeting a replacement will be chosen for the Dutch Psychiatric Association which has so far acted as the secretariat for the Forum. The Forum is now firmly established as the body representing specialist trainees in psychiatry at an international level.

Peter L. Cornwall and Laurence Sheldon, Collegiate Trainees Committee

Correspondence: P. L. Cornwall, Clinical Research Associate, University Department of Psychiatry, Royal Victoria Infirmary, Queen Victoria Road, Newcastle upon Tyne NE1 4LP 